\title{
The Mexican European Diaspora: class, race and distinctions on Social Networking Sites
}

\author{
Abstract \\ This article presents original user-based research concerning a Mexican European \\ Diaspora's use of Social Networking Sites (SNSs) for making racial and classed distinctions \\ through the course of sharing and viewing content on their networked profiles. \\ Bourdieu's theoretical framework is used to address the ways in which SNSs usage \\ fosters social capital, exclusion and displays of prejudice and discrimination. We also found \\ useful the analysis of racial distinctions based on participants' references to physical \\ attributes.
}

To illustrate the use of racial and classed distinctions, we specifically consider the use of Facebook and also of A Small World (ASW), an exclusive SNS, regarded as one of few designed for use by 'the wealthy' (Ruiz, 2008).

We analyse the term "naco", a pejorative Mexican term commonly used to refer to vulgarity or inferiority amongst Mexican European and privileged diaspora with strong racial, classed and gendered connotations.

The empirical material for this study is based on ethnographic research. Through the analysis of displayed images and text as well as well questionnaires and interviews we found tacit or explicit exclusion, discrimination and segregation through close knit SNS networks engaged in by our participants, a Mexican privileged European diaspora.

Keywords: race, class, distinction, Bourdieu, Facebook

\section{The Digital, Racial and Classed Divide}

Some authors have successfully demarcated the history of SNSs in introductory articles such as Boyd and Ellisons' (2007) and Kumar Novak and Tomkins' (2006). Most of the research into cultural practice on the Internet has been published within, and focused on the developed Western world. Almost all-existing work in the study of SNSs has been conducted by European and US academics, focusing on users from developed Western nations. This article aims to include the analysis of a specific diaspora in Europe.

The use of SNSs has clear potential for the creation and reinforcement of groups and networks with political and social purposes, in part since they provide facility for drawing the attention of a huge user base. Some initial studies have begun to address the unique role of 
SNSs in relation to the creation of groups and networks for political, cultural and social activities (Castells, 2009; Gueorguieva, 2008). Some others have focused on how 'race' is articulated through online representations (Nayar, 2015; Franklin, 2003; Nakamura, 2002), which is further discussed here. There is increasingly extensive academic treatment of SNS use, but it is Boyd (2013) who has particularly explored racial classifications in this context. Boyd centered on teenage SNS use in the USA referencing the specific term white flight to make classifications intrinsically related to the analysis made in this article.

According to Internet Live Stats (2018) 60\% of the world population doesn't have an internet connection. SNS use not only depends on internet access but also on leisure time and basic technological skills and literacy. The fact that populations with the least economic resource are the least active online points to the danger of SNS use in compounding the disparity between individuals from relatively privileged backgrounds and the poor of the world. This forum for communication continues to gain importance, which still largely excludes the voices of the poor and underprivileged.

In order to understand participants' conception of class, the importance of cultural norms regarding other differences such as race for any working concept of class or of social status must be understood (Karner 2007; Woodward 2003; Castles, 2000; Gubbay, 2000; Frankenburg, 1993). The significance of the relationship between racial and classed distinctions must certainly vary culturally according to historical factors. Access to positions of power and wealth in Mexico has been delineated by racial differences throughout its history, for much of this time far more markedly than occurs today. Many academic and institutional studies in Latin America and in Mexico (INEGI, 2010; Flórez, Medina y Urrea, 2003) have demonstrated that indigenous groups are commonly amongst the poorest and most underprivileged in Mexican society. In the national and historiographical discourse, most of the Mexican population is considered mestiza (Lozoya, 2008). However, the mestizaje can be understood to be a myth in Mexican culture. The ruling Mexican class has possessed and/or claimed a European legacy, which has reinforced perceptions of class based on racial attributes. Issues related to class were frequently mentioned by respondents in this research and, hence need to be taken into account when analysing SNS use amongst Mexicans.

In Mexico the idea of ethnicity is widely referenced in both institutional and academic discourse, in relation to the need to recognize indigenous groups, a part of the fight against segregation in Mexico. The National Commission for the Development of Indigenous Peoples states that, on the basis of their different languages, between 51 and 54 distinct ethnic 
groups exist in the country (CDI, 2010). As Bartolomé states, institutions for indigenous concerns in Mexico conceive of cultural and linguistic identities as elements of an inseparable whole (1997). However, there may well be a number of additional groups which consider themselves as ethnically distinct. This work refers to a number of distinctions made by SNS users during discussion of SNS use in which they used the term naco. These references tended not to be linked to particular indigenous ethnic groups, but rather to general physical characteristics conceived here as classed and racialized images in the sense elaborated by Wade (1997).

The modern use of the term naco is deeply related to a process of social exclusion which has many of its roots in the Spanish colonization of Mexico (Mendoza, 2004). The economic and social structure of colonial Mexico was for many centuries based on the exploitation and exclusion of indigenous peoples, a history which has set many of the conditions shaping the use of naco and which has contributed to the construction of an idea of the superiority of the white. Mexicans, according to Basave (2011), tend to estimate the socioeconomic condition of someone they encounter, basing this principally on physical appearance. He explains that this implies a racial discrimination which he evidences through examples based on how individuals' physical appearance influences their potential for obtaining certain jobs and receiving certain treatment. When referring to racial categories amongst Mexicans, class must be recognized as intrinsically related.

We agree with Rustin (2000) in emphasizing the need to recognize the interdependence of racial and classed distinctions, since they are related by a cultural, historical, economic and socially specific context in which imperialism and Spanish colonization have played important roles in shaping social norms. In Mexico, racial and classed categories are intrinsically related and bring about practices of social exclusion. Naco is a term whose use is connected with both classed and racial categories. As Basave points out, even if many might argue that naco refers to an individual lacking education rather than whiteness, it is commonly used to insult someone on the basis of their autochthonous aspect (Basave, 2011). It became an insult related to racial and classed based discriminatory practices made by a more socially advantaged minority in reference to the majority (Basave, 2011) differentiated by economic status and physical appearance.

The social attitudes and elitism, which perpetuate these very real social divisions as well as the digital divide, are evident in the interactions, which take place amongst these usually affluent and socially mobile users, although they are not always clear to the users themselves. This study aims to contribute to the analysis of the use of the Internet among 
immigrants, particularly looking at how SNSs can be used to build bridges as has been argued by recent studies of transnational communities of immigrants (Navarrete and Huerta, 2006) and diaspora (Oiarzabal, 2012), particularly Mexican (Gonzalez et.al. 2007; Lange, 2007), while developing an original and critical view of how these can be used to make distinctions based on classed and racial differences among relatively privileged groups.

\section{Methodology}

While exploring the uses of SNSs among Mexican diaspora, some factors signaling the direct relevance of economic and educational resourcefulness were prominent. We sought Mexican SNS users as participants for this research who were born and raised in Mexico, and had been since residing in Europe. According to information provided, most respondents were highly computer literate and used ICT daily, most used their own digital devices; many had university degree level education and knowledge of multiple languages. Many had set up their own successful businesses, or held posts working for international corporations, educational or governmental institutions. We noted that the search for these participants was turning up a relatively privileged demographic of professionals and students, which belonged to the 15 percent of Latin American migrants (Sandoval, 2007) who enjoy financial stability and legal resident status. According to the data collected most participants were engaged in an international lifestyle shown through their photographs of visits to different countries, comments and posts about tastes and preferences for international luxury products and leisure activities.

Participant observation has been commonly applied in online ethnography (e.g., Boyd, 2008; Kendall, 1999; Turkle, 1997). While observation is based on the mere act of watching and scrutinising a social and cultural situation in a specific context, participant observation involves communication and interaction with participants in such a way that the researcher also becomes a participant within the phenomena being observed and analysed. It is commonly agreed that observational techniques in combination with the participant role of the researcher, whether carried out online or offline, are useful tools for ethnographic analysis of different kinds of environments. For example, Kendall, one of the first academics to have explored the world of social relations as they have evolved on the internet, states regarding participant observation that she would "never have the audacity to suggest that all social science research projects ought to include participant observation." Yet with regard to research into interactive online forums, she "would recommend just that" (1999: 57), since 
this is a means for researchers to gain a direct sense of the communication and interaction occurring on a site. This has been widely used in methodologies for ethnographic fieldwork amongst qualitative researchers because it allows a degree of closeness to participants as well as a profound and direct apprehension of and engagement with the communication taking place on a given site. In order to learn and engage with the sites and their users as a researcher, we had to act as an active member and create an online relationship with participants, while also making our investigative intentions and the research process public.

During the period of two years (2009-2011) participant observation of 39 SNS profiles of regular and heavy users between 18 and 39 years of age was conducted. We took notes of observations every time participant observation was carried out, spending 2 to 4 hours every day observing interactions on SNSs, analysing multimedia material posted in the form of written messages, images such as emoticons, photographs and videos, and collecting data from our sample of profiles. We found the participants by creating a profile for research purposes and looking into groups with keywords such as Mexico and Mexican. We did not look for participants in specific countries, but we instead found participants who accepted being included in the research who were living in England, Spain, Finland, Germany, France, Hungary and Switzerland. They were essentially a Mexican European diaspora who identified themselves as international, cosmopolitan and mobile. One limitation of this research was related to the sampling since it relied on an initial network of contacts, many of whom may have possessed somewhat similar social, cultural and economic backgrounds. We enlarged the network by using Facebook's service "people you may know" and joining via each of our own SNSs different groups of Mexicans in order to send invitations out to add users to our contacts' list. The use of groups on SNSs is a notable part of users' construction of identities on these sites and a user's affiliation with a group is commonly a fact shared with their contacts. Such group membership thus acts as an affiliation token which may communicate something about the educational or professional trajectory of the user, (for example in the case of groups of schools, universities, companies and institutions), or something about their tastes and interests (in the case of groups related to hobbies such as scuba diving, hiking, musical bands, literary groups, etc.). By studying comments displayed on these groups we were able to get a sense of the motives behind Mexican users' engagement with groups, both in creating and using them, and their relation to the construction of identities. Part of the methodology was based on the visual analysis of images, videos and other multimedia resources which varied from network to network 
We collected further data on social, cultural and social backgrounds of participants and obtained consent for conducting this research receiving back via email or SNS, 24 completed questionnaires. Also six female and four male participants agreed to conduct indepth interviews carried out online and lasting 40-90 minutes. For all participants pseudonyms were used in this research in order to protect their privacy. The availability and willingness of the participants to be interviewed or to fill out and send back the questionnaires was a limitation on this research. However, we consider that we gathered sufficient data in different forms. Some of the most useful initial data came from photographs used in albums and as profile pictures, along with comments made about these images and also from general comments on links and in profile updates, since this material is commonly found on user profiles and richly illustrates how SNS users construct their identities on these sites and how they are perceived by other users. Qualitative data was analysed textually and visually using ethnographic methods in order to scrutinise the everyday practices of the participants online and to gain a deeper sense of context. According to Banks (2001) visual methods consist of analysis based on the observation and interpretation of still and moving images, and can be useful for social and cultural research. He points out that applying visual methods involves assessing the content of an image by observing and labeling it, but also by adding knowledge to it. This means that researchers need to sociologise the image, or place its reading "within the context of a particular research project" (Banks, 2001:5). Researchers must use their contextual understanding to process the information provided by an image to understand its content as a collection of representations. In addition, social researchers should ask specific questions regarding the content, origins, use and readings of a given image. Visual methods helped us to analyse how research participants negotiated and selected specific self-representations made on their profiles. When analysing images on SNS profiles we followed Banks' advice by observing and interpreting the content of specific images shared on a profile. We collected the material, assessed the content and made notes. We also questioned what was shown when there was any known purpose behind the image having been chosen to be uploaded onto the profile, as well as how a user's contacts responded to and commented on the image.

Pink (2001) points out that combining photograph, video and narratives (often in the form of written text) is useful in analysing the self-representations made by participants. Normally the use of new signs and innovative forms in written language are based on cultural meanings shared by groups of people. For example, whereas in English, using x is normally interpreted as representing a kiss, as in "I love you xx", amongst Mexicans it is common to 
find messages using x instead of the Spanish word "por" which means "for" in English. Therefore, depending on users' cultural background, the same signs may have different meanings which can be understood only according to cultural context. The analysis of signs and codes was an important part of this research. We analysed SNS content in the context of SNS users' profiles; pairing text, photographs, images, comments and other content found in profiles to the information participants provided in their questionnaires and interviews, in conjunction with our field notes.

Respondents signaled their economic wealth through data posted to their SNS profiles, as well as cultural and social attributes associated with a Mexican diaspora of relative privilege. This highly influenced our approach to the analysis of cultural practices on these sites, focusing the research towards the distinctions made by participants, further explored through material collected in questionnaires and interviews.

\section{A Small World: a small class}

According to Bourdieu (1993) the members of the dominant class set the rules and values in the field of cultural production within capitalist societies (e.g., artistic, scientific, journalistic fields, etc.). It could be argued that ASW, a SNS started in 2004, aims at having members from the dominant classes join. Erick Weichmeister, chairman of the site, calls it 'a private international community of culturally influential people who are connected by three degrees', as stated on the homepage (see ASW, 2010). In the welcoming message sent to every new member he stated:

When we say 'What a small world', we think it is a coincidence. It actually reflects how we keep meeting each other because we have similar habits. Privacy and trust are our core values, and we trust your judgment on how you use the site. We live in a small world, and we want to keep it that way. (ASW, 2010)

Online "ethnic communities construct, stabilize, modify, and challenge individual and community senses of identity over a relatively long period of time" (Byrne 2008, p. 17). Being part of ASW is related to having a similar sense of community, collective identification and practices of distinction based on classed differences. According to Byrne, simply belonging to a site where there is a dominant racial or ethnic group does not guarantee that participants' contributions to the site are welcome (Byrne 2008:29). Wachtmeister's 
message suggests that ASW is designed for a specific group of people who are part of a close-knit network, sharing specific characteristics setting them apart from the general public. Those who do not behave according to the established and yet subtle rules of ASW are expelled from it and their profiles are taken to "a big world".

In Mexico, group diversity and heterogeneity are based on ethnic background, racial and classed differences (see Basavé, 2011) despite a general political discourse of homogeneity based on the myth of being a country of mestizos (Lozoya 2008). The mestizo myth is based on the idea that human races can blend together to create a new racial group, in this case the Spanish and indigenous races. In his research Gómez-Peña (2000) offers a selection of 'confessions' about the perception of Mexicans:in which he shows a shared sense of fear of getting kidnapped or killed upon going to Mexico (2000: 41). Updating profiles with personal data detailing hobbies, lifestyles and tastes is regarded as having potentially dangerous consequences by many Mexican users from relatively privileged backgrounds. Martin, a masters' student and participant in this research, explained that being worried about posting content can often be read as a sign of wealth in itself, which could put a user at risk of being a target for kidnapping or extortion. This opinion was expressed frequently by respondents who also mentioned that they regularly visit family in Mexico. Mexican users tend to be aware that they are essentially broadcasting large amounts of data on themselves to a range of contacts, which may be intercepted by some means by third parties, and many expressed concerns about the dangerous implications of this since they could become the targets of extortion.

There is also a phenomenon of acculturation in the country increased by globalization and Mexico's vicinity to the United States. For example, Halloween has become a very common celebration amongst Mexicans and participants were often keen to share photos of their Halloween celebrations on their profiles as well as their offerings for the Day of the Dead. Mexicans who are part of ASW are proud to be Mexican; they are willing to show their ethnic pride by following the same rituals. At the same time there was also a tendency to use such posts as attempts to get together in a European context in which being international is seen as an asset that helps to become part of an exclusive group.

Bourdieu states that 'the distinctive power of cultural possessions or practices (...) tends to decline with the growth in the absolute number of people able to appropriate them' (1984: 227). This distinctive power may be seen as the value accorded to a practice or possession within a given field, and clarifies the role which exclusivity can play in defining the rules of the game. Mariana, a participant studying for her $\mathrm{PhD}$ at one of the most exclusive 
universities in England, has a profile on Facebook and on ASW. She explained her view of ASW as being 'for rich people, a network for the elite' .

\section{A network of connections and exclusion}

An individual has to receive a personalized invitation from an active member of the network or have a membership application approved by an international committee of trustees. Sarah said that she had been asking friends for an invitation to join the site for weeks and had not found anyone. She believes that becoming a member will provide her with "exciting connections" and 'potential new friends'. The implication is all too clear in Wachtmeister's use of the term 'influential', the implication being that the characteristics and "habits" in question are concerned with social sway or influence, and closely connected with social status and class.

One member expressed the following: 'I was sure the real ASW was some exclusive site, where every thread was about private jets, domestic servants in Monaco or Maybach color schemes' or '(...) I have been using it for all my private and business travels, enjoying special rates, upgrades, and free breakfast'. Being part of ASW is in itself commonly treated as a cultural good by users functioning as a mark of distinction which may provide a number of advantages (e.g., job opportunities, free parties and events, accommodation, sales and offers of luxury products) provided the site continues to function as a restricted network. A site update added an annual fee of $£ 75$ in order to receive 'hundreds of incredible privileges from renowned lifestyle, travel and fashion brands, including free hotel stays and upgrades, automatic airline loyalty status and VIP shopping' (ASW, 2016).

According to Bourdieu (1986) social networks must be maintained and promoted over time in order for them to be able to be called upon promptly in the future. Bourdieu argues

1 Mariana uses the term "elite", but we agree with Scott (2008) in considering elite a concept that is often over generalised and which needs to be defined precisely in order to possess analytical value. He distinguishes certain forms of power in specific structures of domination as the main starting point for elitism's conceptualization. Since this thesis is concerned with the use of SNSs by individuals from relatively privileged backgrounds who exercise their power across a range of fields and who are not necessarily part of a close-knit network such as ASW, I will omit use of the concept of elite, applying it only to the case of ASW when it is employed by participants. 
that social capital is mostly made up of social obligations, or network of connections of more or less institutionalised relationships of mutual acquaintance and recognition. Social capital is convertible, in certain conditions, into economic capital (1986:242). According to this argument, social capital is considered as intrinsically related to network membership, which makes it particularly relevant for the analysis of SNSs.

As two of its members state, 'Quite a few members have opened doors for me' or 'ASW provided me with an incomparable platform to make new and lasting friendships when I moved abroad - people who also loved to travel, explore, learn, taste and breathe in all the excitement that international living has to offer' (ASW, 2016). ASW makes the link between social networking and social capital very clear, but this relationship runs through the use of all SNSs, albeit usually in subtler ways.

Juan explained that he had received various invitations to join ASW, but that he did not know how he could use them since his close friends were in Leicester, UK and they would not be able to travel as often as him to cities like Paris or Madrid, where he told me that many of the parties organized by ASW members were held.

Mariana believes that many networks can be 'vicious as well as addictive, but the cost of leaving them is to be left out of the loop'. In her interview, Mariana emphasized the fact that she did not want to use her real name for this investigation since she was afraid of being banned from ASW as a result of her comments concerning the site. ASW is kept small and carefully managed, and has specific rules for its users. For example, someone can be banned from the site for 'inappropriate conduct', which can also happen on other sites such as Facebook, if a user posts a large number of comments which are reported by other users as violent, harmful, or if they have sexually explicit content, or are reported by other users as harassing.

What is special about ASW is the way in which the information posted can be understood as promoting a sense of social exclusion, something reinforced by an on-site agreement on the meaning of 'inappropriate conduct'. Mariana explained that if 'a user of this network does something that might seem naco, they are left out in 'A Big World' from which it is impossible to come back'. 'A Big World' is described by other members as 'the gloomy, sad Limbo where you are kicked out to if you misbehave (...) You don't want to be sent there! Sort of like the town square where the convicts were put in gallows and the populace hurled decomposing vegetables at them...' . One user compared the people sent to this section of the site to animals, saying 'there should be a window into A Big World. Kind of like a zoo', he reinforced his comment by saying 'we should be able to chide, sneer and 
throw peanuts at those in A Big World without them being able to answer'. Mariana pointed out that such naco actions, which might send people into this special section might include 'sending too many friend requests to someone who is ignoring you, claiming that a contact is your friend (in person) when he or she is actually not, posting the wrong photographs...' The term naco was used repeatedly by respondents without any prompting, in questionnaires and in interviews discussing the creation and management of online profiles, as well as within online profiles and group pages.

\section{Naco: a Mexican label}

Amongst Mexicans, the dominant modern use of naco is as a slang term for labelling a person or object pejoratively, and it is strongly featured in racialized and classed images. The word's origins are in the indigenous culture of Mexico and are attached to the indigenous peoples in whose language the etymological roots of the word lie (Martínez, 2006).

Naco can be used as an adjective, a substantive or an adverb and it is a problematic term because of the variety of meanings and daily usages, which it takes in different contexts. The contemporary use of naco can include meanings such as rude, tacky, naughty, awful, or improper. Even within its common contemporary use in slang, it is a label that changes markedly depending on the context of use and cultural, social and economic circumstance. An understanding of this use is undoubtedly a part of Mexican identity; it is a concept that has been used for decades in various spheres of Mexican society and which was understood by the participants of this research as a label with a number of connotations based heavily on racialized and classed images.

Wade's (1997) definitions of race and ethnicity which he applied in a Latin American context are particularly suited to the specific context of Mexican identity. Wade understands both terms as social constructions, concepts which have been created and developed according to the specific contexts of a society's existence, and according to the perceptions and communications of the individuals within that society over time. He suggests that ethnicity relates to social constructions based on cultural variations such as custom, religion, use of symbols, language, dress, etc. which are parts of historical traditions of minorities living within a nation state. In his view, geographical space is also an element that shapes ethnicity since 'social relations become concrete in spatialized form' (Wade, 1997:18). In contrast Wade understands 'race' as a set of social constructions based around actual physical appearance, often related to phenotypical variations, such as skin color, height and facial 
features (1997). In relation to this he explains that:

The brute fact of physical difference exists and people have used these cues to create ranked social categories which are used to include and exclude and which are said to show more or less innate, natural differences which are passed over generations. (Wade, 1997:14)

In this way Wade suggests that 'race' is based on the relation of phenotypical variations to the social, historical and cultural contexts that shape the social attitudes of individuals towards such variations. The relation between race and ethnicity is itself neither fixed nor straightforward; they are overlapping constructions and may change over time and vary in their social use.

The use of naco bears similarities to practices of racial and classed stereotyping occurring in a diversity of cultural contexts (Hartigan, 2005). For example, Lieberson points out that "white trash surfaced briefly as a name for the social discrimination and scorn for lower class whites" (1985: 160). In the United Kingdom, many studies have related use of the word 'chav' to anxieties focused on the white working class (Clark and Garner, 2010:61) which are similar to those associated with the term 'white trash' in the United States. One of the participants opined that, "in Mexico you know your class by the colour of your skin". For many Mexicans, naco is related to the economic condition of the working class, but also to racial attributes often based on the bodily appearance of indigenous people (Bonfil, 1990). Mariana's talked about her grandmother's racialized image of indigenous Mexicans. She explained that for her, dark skin was considered a social disadvantage. Although she was critical towards her grandmother's attitudes, when speaking about others' profile photographs on ASW, she nonetheless emphasized the importance of managing one's personal look according to certain physical characteristics, amongst which she implied the import of bodily appearance. She explained that she was sure that 'many users edit their profile pictures with Photoshop so that they can look even better, more muscular, and whiter'. For Mariana being white and muscular are both physical attributes with a positive connotation emphasized by her association of these terms with looking even better. 


\section{The whiter and cosmopolitan representation}

Upon joining ASW, Mariana uploaded a different profile picture from the one she was using on Facebook. In her new picture her make-up and hairstyle were done up much more carefully, and she also appears whiter in her ASW profile picture. This suggests that for Mariana looking whiter has specific positive connotations, that she has designed her picture so that she can fit in more successfully on ASW and with its prevailing social attitudes. This case study and others like it suggest that SNS use amongst Mexican users from relatively privileged backgrounds may reinforce or encourage certain practices of social exclusion and certain racial attitudes.

Nakamura expresses the idea that the Internet:

...permits a kind of cosmetic cosmopolitanism that perpetuates a digital divide that splits along the axis of racial representations as well as along patterns of computer access organized around racial difference. (Nakamura, 2002: xvi)

Nakamura is exploring the idea that representations of cosmopolitanism on the Internet affect the digital divide itself, since they reinforce existing patterns of discrimination. She emphasizes the importance of external appearance when referring to cosmopolitanism as cosmetic, implying the involvement of racial distinctions. She points out that Asian workers are often portrayed as 'exemplary information workers' while African Americans are often seen 'as outsiders to digital economies and systems of representations' (Nakamura, 2002: xvi). In her study she shows that racial classifications amongst Americans and negative stereotypes of minorities such as the African American are based on representations that reinforce differences of access to the Internet, consequently affecting users' interactions. Nakamura suggests that the making of racial distinctions online prolongs the continued exclusion of racial minorities from gaining Internet access. Other properties such as class, gender, age and education also need to be taken into account when understanding the digital divide. However as Nakamura argues, 'race' seems an important element to consider through the analysis of representations, as it seems to be so closely related to the perpetuation of the digital divide.

According to Nayar, the digital culture is driven by concerns over profit and power which affect people in their real lives. He argues that technology 'must be seen as contextual, and treated as technoculture where meanings, values and functions are integrally associated with the object' (Nayar, 2010:5). The point is that digital cultures are linked and rooted in the 
material world and so are issues of identity and racism. In this context he raises two issues related to identity and race; the construction of 'pseudonymous and anonymous identities' which according to him are more problematic than the issue of 'alternate' identities. Nayar goes on to question 'Do minorities, the disempowered, and the marginalized...' want to surpass the '...matrix of race, community, and gender, and if so do they, or are they capable of doing so? (Nayar, 200:15). The second issue he raises in relation to this concerns representation: 'How is race represented on the World Wide Web? What ideological codes are used to represent race on the Internet? He argues that in 'times of uncertain identities, stereotypes of 'authentic', unchanging, stable 'natives' or the racial Other proliferate. The Other is most commonly the woman and/or the black person. We could argue that studies such as this are important to establish the connection of issues of race in the material world, with its representation in the digital world. In many cases digital representations reproduce the inequalities of the material conditions of minorities and disempowered people.

Boyd (2013) approaches the common use of the term white flight, a concept originally referring to an exodus of white people from urban American centers to the suburbs who wanted to avoid racial integration in the $20^{\text {th }}$ century, an exodus which excluded low income whites. She refers to the frequent use of the term white flight amongst her teen participants in referring to a perceived racial and classed exodus from MySpace to Facebook, explaining that perception of these trends, and of a site's user base, often links to how users choose to use one site over another. Despite the fact that her participants did not refer specifically to race or class, she considers many of their statements to be related to a general perception of Facebook and MySpace user bases as possessing racial and classed characteristics.

\section{Discrimination and gender}

Amongst Mexican adults use of the term naco is negotiated on the basis of perceptions and stereotypes of race that are shaped by particular cultural and social norms. These affect how SNSs are used and selected for use, and are linked to class distinctions made by participants in this research. Lucero pointed out that a reason for her leaving Hi5 was that since her network had expanded, it had become 'full of nacos'. Elena decided to leave Hi5 because 'it was a site for nacos'. Hi5 was the first popular SNS amongst Mexicans, and Facebook when it first became available was regarded by many of my participants as a site for 'users who are up to date' and 'aware of recent online innovations', or 'who can understand the interface'. Facebook was available at first only in the English language. For 
many users Facebook became an opportunity 'to start from scratch, to build a new network and get rid of some undesirable contacts', as Ariel put it.

Lucero explained the following:

Well...I am going to sound terrible here, but for me a naco profile is for example one in which you can see a dark skinned guy with spiky hair wearing a t-shirt excessively highlighting the name of a brand (...) Like those girls who appear in a bikini with their breasts pulled up looking at the camera in suggestive postures (...) Naco is something very vulgar, maybe sexual.

Lucero makes specific sexual references, and her descriptions of naco profiles can be read as racialized images which address representations of bodies with specific phenotypical features of skin color, hair type and taste in clothing. The image of a body in a photograph can inform on a series of characteristics such as height, weight, taste in clothes and body modifications, but it is the ways in which these are interpreted by SNS users that are crucial to understanding how they make distinctions. As Everett points out, the politics of the body 'effectively unmask the damaging power of race body fictions that contemporary gatekeepers positioned inside mainstream and other media outlets often deny, disavow, and deploy all at once'(Everett, 2009: 152). In this case, racialized bodies are not only missing agents but targets of distinction. Excesses of various types related to the physical body were referenced by participants in defining and using the term naco.

When referring to online profiles of Mexican nacas (referring to naco women), some interviewees pointed out a perceived similarity to the British term chav. According to Tyler (2008) in modern Britain chav is principally associated with white (or racially mixed) working class, which suggests that it is a racialized and classed term, just as naco is. When referring to chav females, or chavettes, she explains that they are commonly described as ostentatiously sexualized women who wear grossly revealing clothing. She considers the use of chav to refer to women as often related to physical disgust and a perception of ostentatious accessories, excessive make-up and distasteful clothes (Tyler, 2008). She suggests that use of the term chav is related to an anxiety of the middle classes with marking distinctions, shown by the repetitive use of the term. 'Abuse directed almost exclusively towards the white poor (...) in a way that bears striking similarities to the US white trash figure, and the Australian figure of the Bogan, the chav foregrounds a dirty whiteness - a whiteness contaminated with 
poverty' (2008:15). Tyler makes a clear connection between the distinctions of skin color and economic condition as elements that shape the use of the term chav. Amongst Mexicans related distinctions are seen in the use of the term naco, however it is directed at individuals whose physical characteristics are perceived as non-white.

Laura, a visual artist, described the profile of one of her clients as naca, making reference to the use of Hi5 as other participants did, affirming that "Hi5 is full of nacos".

\section{Lorena: Do you use Hi5?}

Laura: I don't use Hi5, only Facebook. The only person who has asked me to use her Hi5 profile as a source for making her postcard is actually very naca. Her skin is brown and her eyes are slanted. She is also very thin, but like undernourished, you know, not fit.

While emphasizing the sexual pose and selection of colors and photographs made by her client, Laura also noted the possibility that her client may have faced poverty, which may have led to her 'undernourished' looks. As with many other respondents, her image of naca has a highly racial nature, related to bodily appearance and facial features often associated with indigenous peoples.

The use of this term was also related to discrimination based on a specific concept of gender which is visually dominated by pre-established and specific standards of beauty. Though profiles are designed theoretically as unisex technology, their reliance on cultural signs for the creation of an online identity inextricably links the drop-down menu and prompts with a system dominated by patriarchal beliefs. Collectively, societal ideologies which favour youth, Western standards of beauty (thin, white, tall, able-body, etc.), and conformity are dominated by a patriarchal system that genders traits as either 'masculine' or 'feminine', empowering the masculine while devaluing 'the feminine' (Donnelly, 2001).

Although SNS users face the need to negotiate their identities in presenting themselves to contacts from different social circles, users are restricted nonetheless to constructing their profiles according to their own social, cultural and economic resources and even bodily attributes. Using naco to describe an online profile is an example of the use of a discriminatory and derogatory label attached to the expression of certain tastes, preferences, racialized images, lifestyle choices and economic resources. 
Koen (2015) has detailed how relationships between diaspora, gender, youth culture and digital media are articulated in the specific case of second-generation Moroccan- Dutch. He details how digital spaces offer users a chance to enjoy themselves, observe other people and do some (window) shopping. He argues that they are not public domains but that they serve private interests. Users can manipulate the information shown on their profiles, moderate its presentation to suit the impression they wish to make. However, sharing information related to economic prosperity, cultural and social background is quite common amongst SNS users, not only because there are standard formats provided on profiles for doing so, but also because users construct their identities through the selection of preferences, tastes, and images shared on profiles, often presenting different forms of capital as illustrated earlier. The fact remains that this selection will be largely sourced from the cultural, social and economic resources and experiences that have been made available to that individual through their life. Photographs of users' travel to foreign countries, messages referring to expensive plans or luxurious hobbies, attendance at privileged events or important contacts affiliated with users' profiles may all serve as signs both inferring and enhancing their capital resources.

Social capital and its perception is a major factor in users' negotiations over what to omit from their profiles, as well over which networks to join. Users have different attitudes towards what is worth sharing, these are concerns which amongst our participants were typically saturated in an awareness of social differences.

\section{Conclusion}

This article has shown how specific identity constructions can be highly influenced by specific cultural, social and economic backgrounds. Many of the communicative practices observed may be understood as related to users' awareness of social differences. These differences shape the ways users assemble and use their profiles on Hi5, MySpace and Facebook, as well as on other SNSs designed for the privileged such as ASW, and the way in which they read and interpret others' profile content. The style of language and the content of multimedia material may present the user as affiliated with a certain segment of society, or as possessing a certain social class.

This article has also indicated that SNSs provide a way of creating and maintaining social ties that may lead to beneficial social outcomes for users. They provide opportunities to present, consolidate and acquire different forms of social capital. While the case of ASW 
has been detailed here, cases from other SNSs indicate an entrenched set of practices. SNS access constitutes access to unique channels of information. The simple fact of being an SNS user may be considered a form of social capital in that it speaks to a user's capacity to access technology, and because it augments their ability to be social with a wide range of people from different parts of the world and from a range of social circles.

However, as this article has shown, communication through SNSs among relatively privileged Mexican migrants in Europe often involves discriminatory practices that may encourage and reinforce exclusion and segregation. SNS users often partake in a degree of tacit or explicit discrimination associated with specific types of representative practice, especially with regard to racial and classed distinctions. This adds a layer of complexity to the negotiation which users must conduct over what to present on SNSs, as well as indicating the social significance of academic study into SNS use.

Suggestions for future developments in this specific area of study might include the analysis of the use of other social media tools, such as Twitter and applications such as WhatsApp which have become very popular with the increasing use of smart phones. It would also be interesting to investigate how the increasing use of mobile devices has shaped diasporas and the classed and racial practices of discrimination among privileged groups.

\section{REFERENCES}

AMIPCI (2010) Estudio 2009 sobre hábitos de los usuarios de Internet en México, Asociación Mexicana de Internet (online) (Accessed 1 June 2010) at http://www.slideshare.net/diplomadocom/estudio-de-los-hbitos-de-los-usuarios-de-internet$\underline{\text { en-mxico-2010 }}$

Banks, M. (2001) Visual Methods in Social Research, London: Sage.

Bartolomé, M. A. (1997) Gente de costumbre y gente de razón: las identidades étnicas en México, México: Siglo XXI.

Basave, A. (2011) 'Racismo a la Mexicana', El Universal, 16 de Junio 2011 (online)

(Accessed 18 June 2011) at http://www.eluniversal.com.mx/editoriales/53290.html

Bonfil, G. (1990) México profundo. Una civilización negada, México: Grijalbo.

Bourdieu, P. (1984) Distinction: A Social Critique of the Judgement of Taste (Translated by Richard Nice), London: Routledge.

Bourdieu, P. (1986) 'The forms of capital', in J.G. Richardson (ed.) Handbook for Theory and Research for the Sociology of Education, New York: Greenwood Press, pp. 241-258. 
Bourdieu, P. (1993) The Field of Cultural Production, Great Britain: Polity Press.

Boyd, D. (2013) 'White flight in networked publics? How Race and Class Shaped American Teen Engagement with Myspace and Facebook' in Nakamura. L. and Chow-White, P. (ed.) Race after the Internet, Routledge, pp. 203-22.

Boyd, D. M. (2008) Taken Out of Context: American Teen Sociality in Networked Publics (A dissertation submitted in partial satisfaction of the requirements for the degree of Doctor of Philosophy in Information Management and Systems at the University of California), Berkley, United States.

Boyd, D.M. and Ellison, N.B. (2007) Social Network Sites: Definition, History, and Scholarship. Journal of Computer-Mediated Communication, 13(1): article 11 (online) (Accessed 14 June 2008) at http://jcmc.indiana.edu/vol13/issue1/boyd.ellison.html Byrne, Dara N. (2008) 'The Future of (the) "Race": Identity, Discourse, and the Rise of Computer-mediated Public Spheres', in Everett, A. (ed.), Learning Race and Ethnicity: Youth and Digital Media, The John D. and Catherine T. MacArthur Foundation Series on Digital Media and Learning. Cambridge, MA: The MIT Press, pp. 15-38.

Castells, M. (2009) Communication and Power, Oxford: Oxford University Press.

Castles, S. (2000) Ethnicity and Globalization: From Migrant Worker to Transnational Citizen, London: Sage.

CDI (2010) Nombres de Lenguas, Pueblos y Distribución, Comisión Nacional para el Desarrollo de los Pueblos Indígenas, (online) January 19, 2010 (Accessed 10 May, 2010) at http://www.cdi.gob.mx/index.php?option=com_content\&view=article\&id=758\&Itemid=68 Clark, S. and Garner, S. (2010) White Identities: A critical Sociological Approach, New York: Pluto Press.

Donnelly, A. M. (2011) 'Read my Profile: Internet profile culture, young women, and the communication power', in: Ames, M. and Burcon, S. H. (eds.) Women and language: essays on gendered communication across media, Jefferson, N.C: McFarland, pp.167-181.

Everett, A. (2011) 'Have We Become Post-Racial Yet? : Race and Media Technologies in the Age of President Obama', in Nakamura, L. and Chow-White, P. (eds.) Race After the Internet, New York: Routledge Press, pp.146-167.

Flórez, C.E; Medina, C. and Urrea, F. (2003) 'Los costos de la exclusión social por raza o etnia en América Latina y el Caribe', Coyuntura Social, 29 Diciembre, Fedesarrollo, Bogotá, Colombia. 
Frankenburg, R. (1993) White Women and Race Matters. The social construction of whiteness, Minneapolis: University of Minnesota Press.

Franklin, M. (2003) I define my own Identity: Pacific Articulations of Race and Culture on the Internet. Ethnicities, 3(4): 465:490.

Gómez-Peña, G. (2000) Dangerous Border Crossers, US: Canada, Routledge.

González, V. M., \& Castro, L. A. (2007) Keeping strong connections to the homeland via web-based tools: The case of Mexican migrant communities in the United States. Journal of Community Informatics, 3(3), 1-27.

Gubbay, J. (2000) Shifting Classes: Interactions with Industry and Gender Shifts in the 1980s. Sociological Research Online 5(3) (online) (Accessed 20 November 2010) at http://www.socresonline.org.uk/5/3/gubbay.html

Gueorguieva, V. (2008) Voters, MySpace, and YouTube: The Impact of Alternative Communication Channels on the 2006 Election Cycle and Beyond. Social Science Computer Review, 26(3): 288-300.

Hartigan, J. (2005) Odd Tribes: Toward a Cultural Analysis of White people, Duke:

University Press, Durham and London.

Karner, C. (2007) Ethnicity and Everyday Life, Oxon: Routledge.

Kendall, L. (1999) 'Re-contextualizing “cyberspace”: Methodological considerations for online research', in S. Jones (ed.) Doing Internet research: Critical issues and methods for examining the net, Thousand Oaks, CA: Sage, pp.57-74.

Kumar, R., Novak, J., and Tomkins, A. (2006) Structure and evolution of online social networks. Proceedings of 12th International Conference on Knowledge Discovery in Data Mining, New York: ACM Press, pp. 611-617.

Lange, P. G. (2007) Publicly private and privately public: Social networking on YouTube. Journal of Computer-Mediated Communication, 13(1), 361-380.

Leurs, K. (2015) Digital passages youth 2.0: diaspora, gender and youth cultural intersections, Amsterdam University Press.

Lieberson, S. (1985) 'Unhyphenated whites in the United States', Ethnic and Racial Studies 8(1): 159-180.

Lozoya, J. (2008) El discurso sobre la identidad mestiza en la historiografía finisecular mexicana de la arquitectura. Amérique Latine Histoire et Mémoire. Les Cahiers ALHIM, 16 (online) (Accessed 4 January 2010) at http://alhim.revues.org/index2994.html 
Martínez, G., R. (2006) El neonahualismo y otras evoluciones contemporáneas. Alteridades, enero-junio, Universidad Autónoma Metropolitana - Iztapalapa, Distrito Federal, México, 16 (31): 107-177.

Mendoza, V. (2004) Fenomenología Crítica para el Análisis del Uso Lingüístico de los Actos de Habla de Exclusión: los Nacos. Razón y Palabra (38) (online) (Accessed 10 March 2007) at http://www.www.razonypalabra.org.mx/anteriores/n38/vmendoza.html

Nakamura, L. (2002) Cyberspace: Race, Ethnicity, and Identity on the Internet, New York: Routledge.

National Institute of Statistic and Geography (INEGI) (2010) Demografía y Población (online) (Accessed 13 December 2010) at http://www.inegi.org.mx/Sistemas/temasV2/Default.aspx?s=est\&c=17484

Navarrete, C., \& Huerta, E. (2006) Building virtual bridges to home: The use of the Internet by transnational communities of immigrants. International Journal of Communications, Law and Policy (online) (Accessed, 10 May 2015) at http://papers.ssrn.com/sol3/papers.cfm?abstract_id=949626

Nayar, Pramond K (2010) An Introduction to New Media and Cybercultures, UK: WileyBlackwell.

Oiarzabal, P. J. (2012) Diaspora Basques and online social networks: an analysis of users of Basque institutional diaspora groups on Facebook. Journal of Ethnic and Migration Studies, 38(9), 1469-1485.

Pink, S. (2001) Doing visual ethnography: Images, media and representation in research, Thousand Oaks, CA: Sage Publications.

Ruiz, N. (2008) Five Social Networking Sites for the Wealthy. Forbes (online) (Accessed, 11 June 2010) at http://www.forbes.com/2008/05/02/social-networks-vip-tech-personalcx_nr_0502style.html

Rustin, M. (2000) 'Psychoanalysis, racism and anti-racism', in P. DuGay (et. al.) Identity: a reader, London: Sage, pp.183-201.

Sandoval, É. R. (2007) Migración y desarrollo en América Latina: ¿círculo vicioso o círculo virtuoso? Pensamiento iberoamericano, pp. 153-180.

Scott, J. (2008) Modes of power and the re-conceptualization of elites. The Sociological Review, 56(s1), pp. 25-43.

Turkle, S. (1997) 'Life on the Screen: Identity in the Age of the Internet', London: Phoenix. Tyler, I. (2008) '”Chav Mum, Chav Scum”: Class Disgust in Contemporary Britain', 
Feminist Media Studies, 8(1): 1-18.

Wade, P. (1997) Race and Ethnicity in Latin America, Pluto Press, Chicago.

Woodward, K. (2003) Social Sciences: the big issues, Routledge: Oxford.

\section{REFERENCED WEBSITES}

A Small World http://www.asmallworld.net

Hi5 http://www.hi5.com

Facebook http://www.facebook.com

MySpace http://www.myspace.com

Twitter www.twitter.com

Internet Live Stats (2018) (Accessed, 12 February 2018) at

http://www.internetlivestats.com/internet-users/ 